\title{
Formation of Aluminum Microsphere by Utilizing Atomic Migration
}

\author{
Faizul Mohammad Kamal", Md. Nazrul Islam Khan \\ Materials Science Division, Atomic Energy Centre, Dhaka-1000, Bangladesh \\ Corresponding author: kamal_ndt@yahoo.com
}

\begin{abstract}
A technique using the sudden change in the geometrical shape of metal line is considered for effective accumulation of atoms, and therefore fabrication of micro/nano materials utilizing electromigration. The experimental sample of Al metal line is formed on a TiN layer and covered with a $\mathrm{SiO}_{2}$ passivation layer. Thereafter, the sample is placed on a ceramic heater under atmospheric conditions, and subjected to a constant direct current for fabricating micro/nano materials. Finally, microsphere was obtained at the specific location in the sample with a sudden change in geometrical shape where a hole was introduced in the $\mathrm{SiO}_{2}$ passivation and Al layers. Therefore, the temperature distribution was observed along the metal line of the proposed $\mathrm{Al}$ sample structure. As a result of current applying, the sphere of a high aspect ratio was fabricated.
\end{abstract}

Keywords: Micro materials, Electromigration, Aluminum, Microsphere, Accumulation.

\section{Introduction}

Most of the research work has been employed a 'bottom-up' approach, which is a method for controlling atoms and molecules, etc., to make fine structures. The various bottom-up approaches could be classified into two types, as determined by the growth mechanism. The first type depends on chemical reactions, such as vapor-liquid-solid (VLS) growth [1], template-based synthesis [2], electrochemical deposition [3, 4] and hydrogen reduction $[5,6]$. The other type is based on physical phenomenon approaches, such as electromigration [7-9] and stress migration [10-12]. Metallic atoms are transported by electron wind due to high current density of the metal line utilizing electromigration. The amount of atoms transportation depends on current density and temperature of the line. In some cases, void was formed in electromigration of atoms. On the other hand, hillock was formed at some locations where accumulation of atoms occurred. Therefore, various micro materials such as micro-wire [13], micro-belt [14], micro-tube [15] have been studied and synthesized. An alternative to the different techniques mentioned above is the formation of Al microstructures at predetermined positions by electromigration.

A new mechanism for selectively forming metallic micro/nano materials with different shapes and formation is studied and synthesized in previous works [16]. In the present research, a technique of generating metallic metal of microspheres has been proposed by utilizing electromigration. In the present paper, the new findings are reported on using a sudden change in area of a sample based on the use of electromigration. The sudden change in the geometrical shape of the metal specimen could be expected to enhance for effective accumulation of atoms. Finally, fabrication of microsphere has been happened.

\section{Experimental procedure}

Figure 1 schematically shows a sample structure, which is a passivated Al line with a small hole at the location of metal. Figure 2 shows the cross-sectional view of the sample. The test sample was fabricated as follows. A $290 \mu \mathrm{m}$ thick $\mathrm{Si}$ wafer was oxidized to form a $300 \mathrm{~nm}$ thick $\mathrm{SiO}_{2}$ layer, and then a $300 \mathrm{~nm}$ thick titanium nitride (TiN) layer was deposited on the $\mathrm{SiO}_{2}$ layer by sputtering. After that, a $600 \mathrm{~nm} \mathrm{Al}$ film was deposited on the TiN layer by vacuum evaporation. Following this, the $\mathrm{Al}$ and $\mathrm{TiN}$ layers were patterned by wet etching and fast atom beam (FAB) etching, respectively. Then a $2.4 \mu \mathrm{m}$ thick $\mathrm{SiO}_{2}$ film was deposited on the surface of the sample by plasma-enhanced chemical vapor deposition (PE-CVD) using tetraethyl orthosilicate (TEOS) as a source. Subsequently, the $\mathrm{SiO}_{2}$ film was wet etched to expose the pads to current supply. Finally, a $1 \mu \mathrm{m}$ diameter hole was etched by focused ion beam (FIB) etching. It was confirmed by the end-point detection that the hole would be etched at the Al/TiN interface. Schematically sample structure, which is shown in Fig. 1, used in the experiment. Length of the metal line was $100 \mu \mathrm{m}$. Width of Part A and B of the sample were $10 \mu \mathrm{m}$ and $200 \mu \mathrm{m}$ respectively, where the thickness remained homogenous all through the metal line.

The sample was placed on a ceramic heater under atmospheric conditions, and a constant temperature (i.e., $623 \mathrm{~K}$ ) was maintained. The samples were then subjected to a constant direct current flow using a pair of probes in contact with the input and output pads. Therefore, during the experiment, current flowed from anode to cathode, and electrons flowed in the opposite direction of current making the mass transport of metal atoms. 


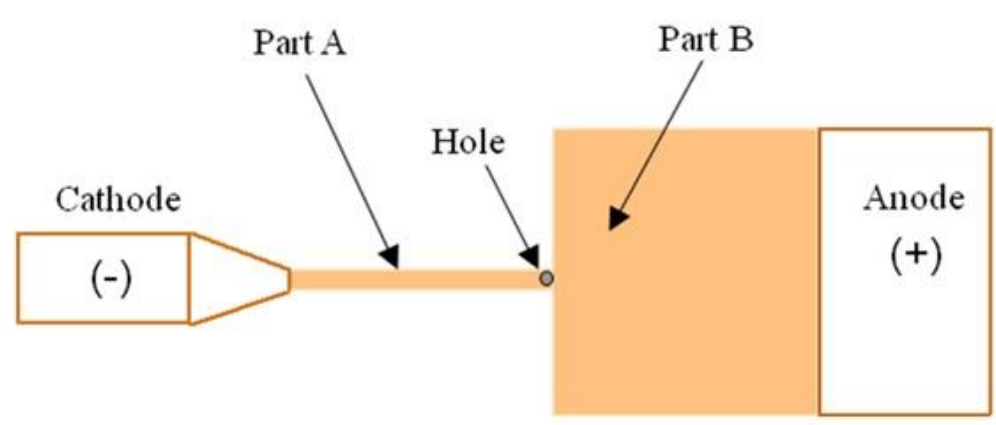

Figure 1: Sample structure used in the experiment.

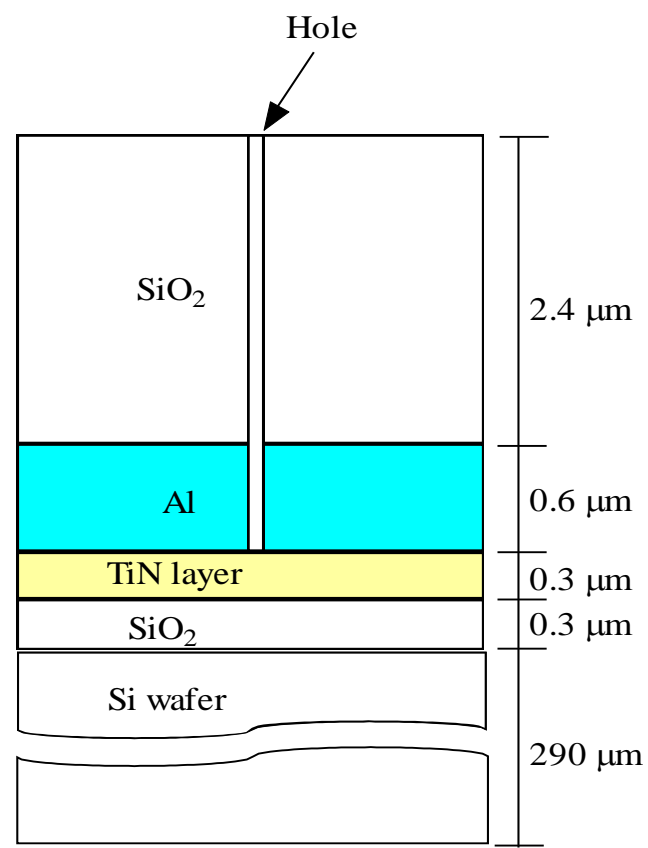

Figure 2: Cross-sectional view of the sample structure.

\section{Results and discussion}

An Al metal sample of $600 \mathrm{~nm}$ thick with passivation layer of $2.4 \mu \mathrm{m}$ was used for the experiment. Sample structure with a width ratio of 1:20 was used in this study. The structural dimensions of the experiment of the sample was used in this study are shown in Table I. Several values of test conditions of temperature and current density were used to optimize the experimental conditions. The experimental results obtained for each condition are shown in Table II.

Table I: Dimensions of the samples

\begin{tabular}{|c|c|c|c|c|}
\hline Sample type & $\begin{array}{c}\text { Width of } \\
\text { Part A }\end{array}$ & $\begin{array}{c}\text { Structural dimensions }(\mu \mathrm{m}) \\
\text { Width of } \\
\text { Part B }\end{array}$ & Hole diameter $(\mu \mathrm{m})$ \\
\hline $\mathrm{S}$ & 10 & 200 & 100 & 1 \\
\hline
\end{tabular}

Table II: Test conditions used in experiments

\begin{tabular}{|c|c|c|c|}
\hline Sample & $\begin{array}{c}\text { Substrate temperature, } \\
T_{s}(\mathrm{~K})\end{array}$ & $\begin{array}{c}\text { Current density, } \\
J\left(\mathrm{MA} / \mathrm{cm}^{2}\right)\end{array}$ & $\begin{array}{c}\text { Current stressing } \\
\text { time, } t \text { (min.) }\end{array}$ \\
\hline $\mathrm{S}$ & 623 & 7.5 & 28 \\
\hline
\end{tabular}


The sample surface was examined by using field emission - scanning electron microscopy (FE-SEM). Microsphere was obtained at the specific position in the sample with sudden change in geometrical shape, which is shown in Fig. 3. A fine Al Microsphere was successfully observed under the condition of current density, $j=$ $7.5 \mathrm{MA} / \mathrm{cm}^{2}$ and substrate temperature, $T_{s}=623 \mathrm{~K}$. Current stressing time, $t$ was happened at $28 \mathrm{~min}$. The diameter of the microsphere is $4.6 \mu \mathrm{m}$.

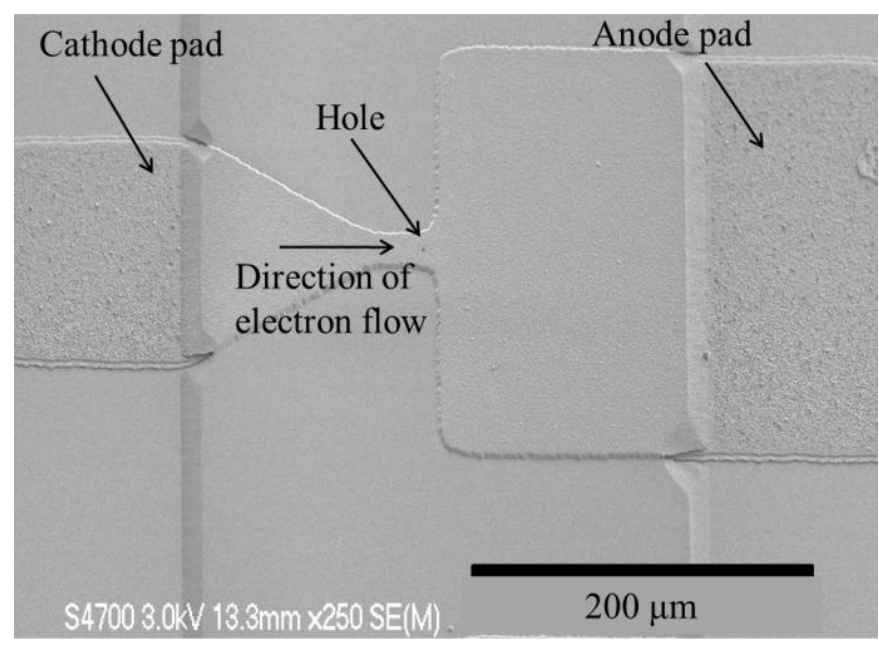

(a)

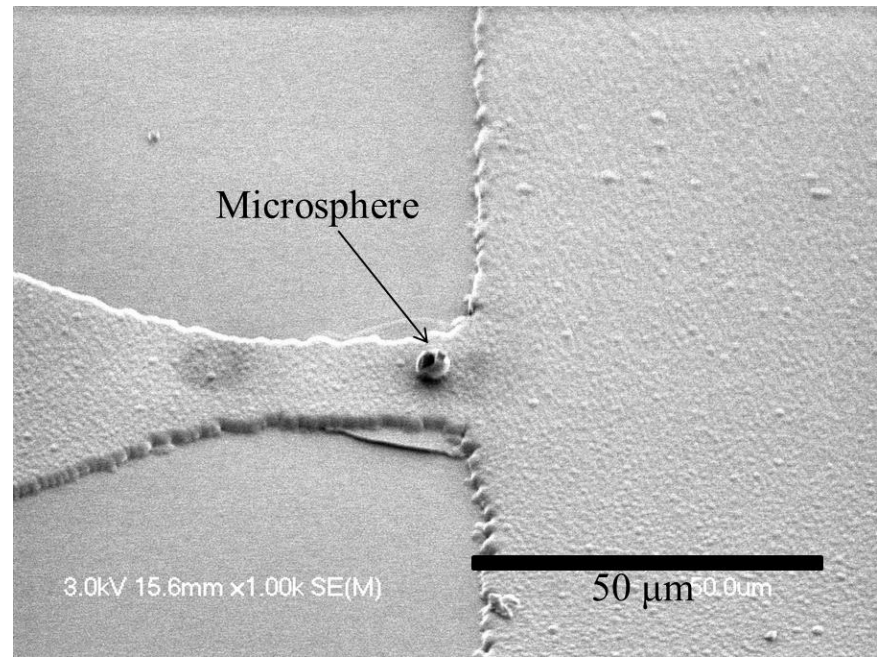

(b)

Figure 3: FE-SEM images- (a) experimental sample with a hole at specific position, and (b) formation of microsphere observed after experiment at the predefined location.

Electromigration (EM) is a physical phenomenon that metallic atoms are transported by an electron wind due to high current density in the metal line. The amount of atoms that are transported depends on the current density, temperature and microstructure of the metal line [17, 18]. The electron wind due to current density can drive metallic atoms to a specific location in a structure in a simple and efficient way. By utilizing this concept, EM can be used to grow fine micro and nano metallic structures. Therefore, controlling the accumulation and discharge of metallic atoms, micro and nano materials can be produced. In the present study, the effective accumulation of atoms happened in a specific location of the sudden change in geometrical shape of the width of the metal line, and finally, microsphere was obtained on this structure.

The model of the sample, shown in Fig. 4, was electrically and thermally insulated. This model can be utilized for evaluating and explaining the experimental results by solving the electro-thermal consideration. For evaluating the constant direct current, $I$, and temperature, $T$, of the sample is maintained. Therefore, the temperature distribution was obtained along the metal line of the Al sample, which is shown in Fig. 5. 


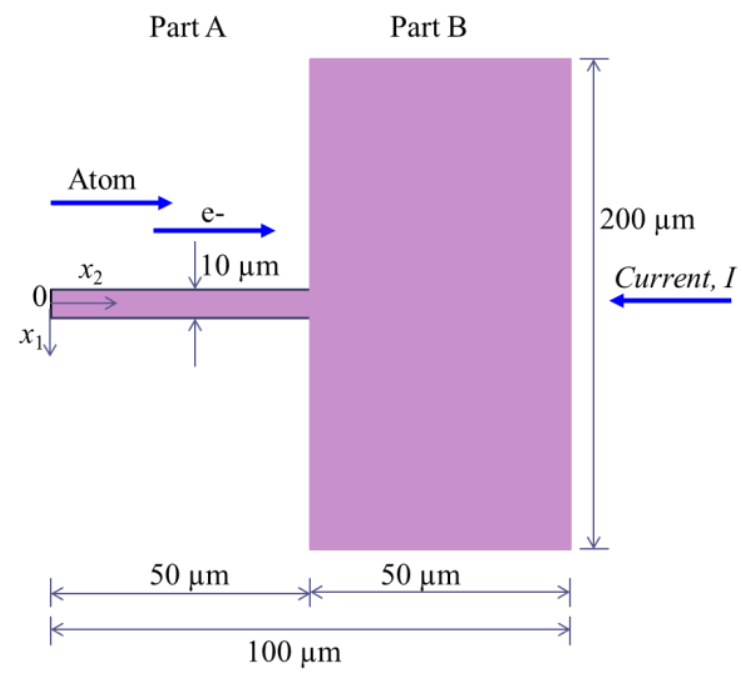

Figure 4: Schematic illustration of shape and dimensions of the specimen used for the experiment.

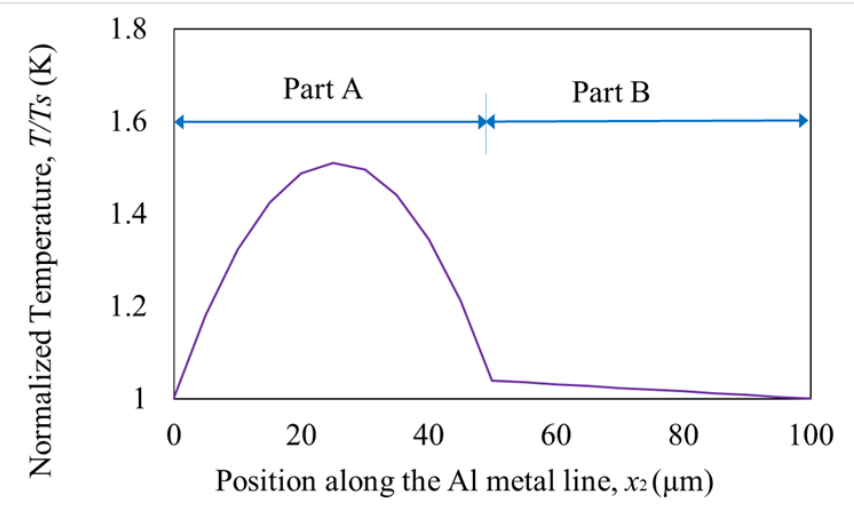

Figure 5: Temperature distribution along the sample line. The temperature distribution suddenly changes at $x_{2}=$ $50 \mu \mathrm{m}$ due to the change in the width of the metal line.

Microsphere was formed in Part A of the sample structure due to high temperature. Thereafter, due to the higher temperature and current density, more atoms were diffused in part $\mathrm{A}$ and fewer atoms were diffused due to lower temperature in Part B. Moreover, due to high temperature and high current density in Part A, more atoms were migrated and accumulated at the sudden change in the geometrical shape suddenly. Finally, more atoms were accumulated at the specific location and compressive stresses are generated and discharge of the atoms at the predefined location happened. After the situation, the atoms are solidified and finally atoms were come out through the hole to release the compressive stress and microsphere was formed. Therefore, the sudden change of geometrical shape in the metal line of a sample can be used for effective accumulation of atoms to produce microspheres materials.

\section{Conclusions}

In this work, an effective method has been proposed using sudden change in geometrical shape of the metal line for forming metallic micro/nano materials. Microsphere was successfully fabricated using electromigration method where the accumulation of the atoms has been controlled by high temperature gradient. The present technique is expected to be utilized to fabricate various micro/nano materials by optimizing the sample dimensions and current stressing condition. Therefore, utilizing of this new methodology has surely a possibility to fabricate several micro/nano spheres of different materials at predetermined positions.

\section{Acknowledgments}

Part of the experimental work was carried out at the Micro/Nano-Machining Research and Education Centre of Tohoku University, Japan. The simulation was performed using supercomputing resources at the Cyberscience Center of Tohoku University. 


\section{References}

[1]. R. S. Wagner and W. C. Ellis, "Vapor-liquid-solid mechanism of single crystal growth," Applied Physics letter, Vol. 4, No. 89 (1964), pp. 89-90.

[2]. R. M. Penner and C. R. Martin, "Controlling the morphology of electronically conductive polymers," Journal of Electrochemical Society, Vol. 133, No. 10 (1986), pp. 2206-2207.

[3]. M. Tian, J. Wang, J. Snyder, J. Kurtz, Y. Liu, P. Schiffer, T. E. Mallouk and M. H. W. Chan, "Synthesis and characterization of superconducting single-crystal Sn nanowire,” Applied Physics Letter, Vol. 83, No. 8 (2003), pp. 1620-1622.

[4]. M. Motoyama, Y. Fukunaka, T. Sakka, Y. H. Ogata and S. Kikuchi, "Electrochemical processing of Cu and Ni nanowire arrays," Journal of Electroanalytical Chemistry, Vol. 584, No 2 (2005), pp. 84-91.

[5]. S. S. Brenner, "The growth of whiskers by the reduction of metal salts," Acta Metallurgica, Vol. 4, No. 1, (1956), pp. 62-74.

[6]. J. Zhang, X. Qing, F. Jiang and Z. Dai, "A route to Ag-catalyzed growth of the semiconducting $\mathrm{In}_{2} \mathrm{O}_{3}$ nanowires," Chem. Phys. Lett., Vol. 371, No. 3-4 (2003), pp. 311-316.

[7]. I. A. Blech and E. S. Meieran, "Electromigration in thin Al films," Journal of Applied Physics, Vol. 40, No. 2 (1969), pp. 485-491.

[8]. J. R. Black, "Electromigration - a brief survey and some recent results," IEEE Transacions on Electronic Devices, Vol. ED-16, No. 4 (1969), pp. 338-347

[9]. P. S. Ho and T. Kwok, "Electromigration in metals," Reports on Progress in Physics, Vol. 52, No. 3, (1989), pp. 301-348.

[10]. C. Herring, "Diffusional viscosity of a polycrystalline solid," Journal of Applied Physics, Vol. 21 (1950), pp. 437-445.

[11]. M. A. Korhonen, P. Borgesen, K. N. Tu and C. Y. Li, "Stress evolution due to electromigration in confined metal lines,"Journal of Applied Physics, Vol. 73 No. 8 (1993), pp. 3790-3799.

[12]. M. Saka, M. Yamaya and H. Tohmyoh, "Rapid mass growth of stress-induced nanowhiskers on the surfaces of evaporated polycrystalline Cu films," Scripa Materialia, Vol. 56, No. 12 (2007), pp. 1031-1034.

[13]. M. Saka and R. Nakanishi, "Formation of Al thin wire by utilizing controlled accumulation of atoms due to electromigration,", Materials Letters, Vol. 60, No. 17-18 (2006), pp. 2129-2131.

[14]. Y. Lu and M. Saka, "Fabrication of Al micro-belts by utilizing electromigration," Materials Letters, Vol. 63, No. 26 (2009), pp. 2227-2229.

[15]. Y. Lu, H. Tohmyoh and M. Saka, "Forming microstructures by controlling the accumulation and discharge of al atoms by electromigration," Journal of Physics D: Applied Physics, Vol. 44, No. 4 (2011), pp. 1-7.

[16]. F. M. Kamal, F. R. Zaki and M. Saka, "Formation of hillock by utilizing electromigration," Journal of the Bangladesh Electronics Society, Vol. 13, No. 1-2 (2013), pp. 121-127.

[17]. H. B. Huntington and A. R. Grone, "Current induced marker motion in gold wires," Journal of Physics and Chemistry of Solids, Vol. 20, No. 1-2 (1961), pp. 76-87.

[18]. I. A. Blech, "Electromigration in thin Aluminum films on titanium nitride," Journal of Applied Physics, Vol. 47, No. 4 (1976), pp. 1203-1208. 